\title{
Seçilmiş OECD Ülkelerinin Ruh Sağlığı Hizmetleri Etkinliğinin Değerlendirilmesi
}

\author{
Evaluation of Mental Health Services Efficiency of Selected OECD Countries \\ Cuma Çakmak ${ }^{a, *}$, Murat Konca ${ }^{b}$ \\ a Arş. Gör., Hacettepe Üniversitesi, İktisadi ve İdari Bilimler Fakültesi, Sağlık Yönetimi Bölümü, 06250, Ankara/Türkiye \\ ORCID: 0000-0002-4409-9669

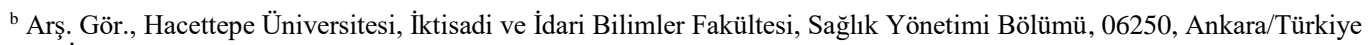 \\ ORCID: 0000-0002-6830-8090
}

\section{MAKALE BILGİSI}

\section{Makale Geçmişi:}

Başvuru tarihi: 22 Mayıs 2018

Düzeltme tarihi: 30 Temmuz 2018

Kabul tarihi: 03 Eylül 2018

\section{Anahtar Kelimeler:}

Ruh Sağlığı Hizmetleri

Etkinlik

Veri Zarflama Analizi (VZA
ÖZ

Ruh sağlığı hastalıkları tüm dünyada giderek artmaktadır. Gerek bireylerin refahı ve sağlığı gerekse ekonomik ve sosyal sistemler üzerine olan etkisi, ruh sağlığı hizmetlerini önemli kılmaktadır. Bu önemine rağmen, ruh sağlığı hizmetleri sağlık sistemleri içerisinde politika önceliği bakımından gerilerde görülmektedir. Ruhsal hastalıkların sebep olduğu sosyal ve ekonomik kayıpların artması, ruh sağlığı hizmetlerinin etkinliğini gündeme getirmektedir. Bu çalışmanın amacı, seçilmiş OECD ülkelerinin ruh sağlığı hizmetleri performansının değerlendirilmesi ve söz konusu ülkeler arasında karşılaştırma yapmaktadır. Bu kapsamda girdi yönelimli veri zarflama analizinin (VZA) ölçeğe göre sabit (CRS) ve değişken getirili (VRS) modellerinden faydalanılmıştır. Girdi değişkenleri olarak; psikiyatri hasta yatağı sayısı, psikiyatri sayısı, psikiyatri hemşiresi sayısı ve psikolog sayısı; çıktı değişkeni olarak ise, kaba intihar hızı kullanılmıştır. CRS Modeline göre üç, VRS Modeline göre dört ülke etkin bulunmuş̧tur. Ülkelerin ruh sağlığı hizmetlerini geliştirerek kaba intihar hızlarını düşürecek önlemler almaları önerilmektedir.

\section{A B S T R A C T}

Mental health diseases are increasing all over the world. Mental health services' impacts on welfare and health of the individual in addition to economic and social systems make them important. Despite this importance, mental health services are among the areas with low policy priority in health systems. The increase in social and economic losses caused by mental illness brings the effectiveness of mental health services to the agenda. The aim of this study is to assess the performance of mental health services of selected OECD countries and to make comparisons among them. In this context, input-oriented Data Envelopment Analysis (DEA) with both Constant Return to Scale (CRS) Model and Variable Return to Scale (VRS) Model has been utilized. In the study; number of psychiatric patient beds, number of psychiatry, number of psychiatric nurses and number of psychologists were used as input variables and as the output variable, the crude suicide rate was used. According to the CRS Model, three countries and according to the VRS Model, four countries were found efficient. It is suggested that countries should take measures to reduce the rate of suicide by improving mental health services.

\section{Giriş}

Ruh sağlığı, sağlığın vazgeçilmez bir parçasıdır ve Dünya Sağlık Örgütü (DSÖ) tarafindan "her bireyin kendi potansiyelini gerçekleştirdiği, yaşamın normal stresleriyle baş edebilecek kapasitede olduğu, verimli ve yararl bir şekilde çalışabileceği ve kendi toplumuna katkıda bulunabileceği bir refah hali” olarak tanımlanmıştır (WHO, 2018a). Ruh sağlığı ya da psikolojik iyi olma durumu, bir bireyin; ilişki kurma, ilişkileri sürdürme, çalışma, boş zaman etkinliklerini değerlendirme, eğitim, istihdam, konut veya diğer seçenekler hakkında günlük kararlar verme becerisi de dâhil olmak üzere tatmin edici bir yaşam sürdürme kapasitesinin ayrılmaz bir parçasıdır. Bir kişinin karşılaştığı mental sorunlar, bu kapasiteyi ve yapılan seçimleri olumsuz etkilemekle birlikte, yalnızca bireysel düzeyde işleyişin

* Sorumlu yazar/Corresponding author.

e-posta: cumacakmak@ hacettepe.edu.tr 
azalmasına değil, aynı zamanda hane halkı ve toplum için büyük refah kayılarına da yol açabilmektedir (WHO, 2013:7). Ruhsal hastalıklar, dünya çapında hastalık yükünün en hızlı büyüyen kategorilerinden birini oluşturmaktadır. Ruhsal hastalıklar; bireyler, aileler ve toplumlar üzerinde yıkıcı etkilere sahip olabilmekte ve her iki kişiden birinin yaşamları boyunca herhangi bir mental bozukluğa yakalandığı ifade edilmektedir (OECD, 2018a).

Birleşmiş Milletler (2014:8) raporuna göre, ruh sağlı̆̆1 problemleri ve yıkıcı davranış bozuklukları, ergenler ve gençler üzerinde uyum sorunlarının önde gelen nedenleri arasındadır. Ruh sağlığı sorunlarının bir milyardan fazla gencin gelişimine olumsuz etkisi mevcuttur ve gençlerin, istihdam edilebilirlik dâhil olmak üzere sosyal ve ekonomik yönden topluma entegrasyonuna zarar vermektedir.

Ruh sağlığı, küresel sağlığın önemli bir yönünü oluşturmakla birlikte insan refahı üzerinde ciddi etkisi olan fakat ihmal edilmiş bir sağlık hizmeti alanıdır (Horton, 2007:806). Ülkeler incelendiğinde, ruh hastalıklarının yükü ile ruh sağlığı hizmetleri için ayrılan kaynaklar arasında büyük bir orantısızlık mevcut olduğu görülmektedir ve mevcut ruh sağlığı hizmetleri de adil bir şekilde dağıtılmamaktadır (Songur vd., 2017:280-281). Ruh sağlı̆̆ı hizmetleri, politika önceliği bakımından diğer sağlık hizmetlerinden daha gerilerde görülmektedir. $\mathrm{Bu}$ gerçeğe rağmen, zayıf ruh sağlığının sadece sağlık değil aynı zamanda diğer sektörler üzerinde de etkili olduğu kabul edilmektedir (Taipale, 2001: 531). Ruh sağlığı hizmetlerinin politika önceliği olarak görülmemesi ve ihmal edilmesinin nedenleri arasında; ülke sağlık sistemlerinde yaşanan başarısılıklar, siyasi liderlik ve öncelik belirlemede problemlerin olması, bu alana yapilan maddi destek yetersizliği, ruh sağlığının birinci basamak sağlık hizmetlerine entegre edilememesi, ruh sağlı̆̆ alanında eğitimli sağlık çalışanlarının yetersizliği ve ruh sağlığı hizmetlerinde halk sağlığı bakış açısının zayıflığı veya bu bakış açısının içselleştirilememesi gösterilmektedir (Horton, 2007:806). Ruh sağlığı ve ruhsal hastalıklar, DSÖ Avrupa Bölgesinde önemli bir halk sağlığı sorunu olarak görülmektedir (WHO, 2003:1). Bununla birlikte, sadece DSÖ Avrupa Bölgesi için değil, aynı zamanda tüm dünyada ruh sağlığı ve ruhsal hastalıkların önemli bir problem haline gelmeye başladığı ifade edilmektedir. Milenyumun ilk yıllarında yapılan bazı çalışmalar ruh hastalıklarının; dünyadaki hastalık yükünün \%14'ünü, Avrupa'daki hastalık yükünün \%20'sini oluşturduğunu ve DSÖ Avrupa Bölgesi nüfusunun üçte birinin ruhsal bozukluklardan muzdarip olduğu ortaya koymaktadır (Taipale, 2001; WHO, 2003: 1; Jacobs ve Mcdaid, 2009: 426). Yakın tarihli bir çalışmaya göre ise, ruh sağlığı bozuklukları küresel hastalık yükünün; engelliliğe ayarlanmış yaşam yılına (DALY) göre \%13'ünü, engelli yaşam yılına (YLD) göre \%32'sini oluşturmaktadır (Vigo vd., 2016: 171).

Yapılan araştırmalarda, yaygın bir ruhsal bozukluğu olanların \%80'inin ve ağır bir ruhsal bozukluğu olanların da \%50'sine yakın bir kısmının herhangi bir tedavi arayışı içerisinde olmadığı veya yeteri kadar tedavi almadığı ifade edilmektedir (OECD, 2018a). Buna ek olarak, ruhsal bozuklukların en çok yoksul ve yoksunluk içerisinde olan insanlar arasında yaygın olduğu görülmektedir. Ruh sağlığı problemi olan insanların olmayanlara kıyasla daha kötü eğitim ve çalışma sonuçları ortaya koydukları belirtilmektedir. Ayrıca, ruhsal bozuklukların erkekleri ve kadınları farklı şekilde etkilediği de bilinmektedir. Örneğin, depresyon kadınlarda iki kat daha yaygın iken, depresyona girenlerde intihar hızı erkeklerde daha fazladır (WHO, 2003:1; OECD, 2018a).

Ruhsal sağlık problemleri, ağırlıklı olarak toplumlar ve ekonomiler üzerinde etki yaratmaktadır. Ruhsal sağlık problemlerinin yarattığı ekonomik yükün gayri safi yurtiçi hâsılanın (GSYH) \%4'üne tekabül ettiği belirtilmektedir (OECD, 2018a). Zayıf ruh sağlığ kaynaklanan maliyetlerin, sadece Avrupa Birliği'nde (AB) GSYH'nin \% 3 ila \% 4'ünü oluşturduğu tahmin edilmektedir. Ancak bu ülkelerin hiçbiri GSYH'nin \% 1 'inden fazlasını ruh sağlığı hizmetlerine ayırmamaktadır (Knapp vd., 2007:172). Sağlık ve sosyal bakım arasındaki farklılıklar dolayısıyla ülkeler arası karşılaştırma yapmak zorlaştırmaktadır ancak sağlık sistemlerinden ruh sağlı̆̆ına yapılan finansman AB'de farklılıklar göstermektedir. İngiltere'de yaklaşık \%14 civarında bir finansman yapılırken Bulgaristan, Çek Cumhuriyeti (Çekya), Polonya ve Portekiz'de bu oran \%4'ten daha azdir (Jacobs ve Mcdaid, 2009: 426). Türkiye'de ise, ruh sağlığı hizmetlerine ayrılan özel bir bütçe bulunmamakta; bu hizmetlerin bedeli, sosyal sigorta, özel sigorta, vergiler ya da kişilerin kendi ceplerinden yaptıkları harcamalarla finanse edilmektedir (Akarçay, 2013: 29-30). Bloom vd. (2011: 27), 2030 yılına kadar ruhsal hastalıklardan kaynaklı olarak 6 trilyon ABD Doları civarında bir ekonomik kaybın olacağını tahmin etmektedir. Toplam maliyetin yaklaşık üçte ikisi dolaylı maliyetlerden, geri kalanın ise doğrudan maliyetlerden kaynaklanacağ ifade edilmektedir. Şu anda, yüksek gelirli ülkeler, bu yükün yaklaşık \%65'ini omuzlamaktadır. Bu durumun 2030'lu yıllara kadar da değişmesi beklenmemektedir. Böyle bir tahmin yalnızca halk sağlı̆̆ı için değil, aynı zamanda ekonomik kalkınma ve toplumsal refah için de önemli bir endişe olarak ifade edilmektedir (WHO, 2013:7).

Görüldüğü üzere gerek politika önceliği olarak görülmemesi gerek ruh sağlığı hizmetlerine yapılan yatırımların ve ayrılan kaynakların yetersizliği, ülke sağlık sistemleri için ciddi bir eksikliktir. Ruh sağlığı hizmetlerinin yarattığı etkilerin yelpazesi geniştir. Bu bağlamda, ülke sağlık sistemlerinin etkinliklerinin incelenmesinde ruh sağlı̆̆ hizmetleri ayrı bir önem teşkil etmektedir. Sayılan nedenlerden ötürü bu çalışmanın amacı, seçilmiş OECD ülkeleri arasında belirlenen değişkenler kapsamında ülkelerin ruh sağlı̆̆ hizmetlerinin performanslarının veri zarflama analizi (VZA) ile değerlendirilmesidir. Bu bakış açısıyla bu çalışmada, ülkeler arasında etkin ruh sağlığı hizmetlerine sahip olan ülkeler ortaya konulmuş ve diğer ülkeler ile karşılaştırılması yapılarak önerilere yer verilmiştir.

\section{Yöntem}

VZA, amaç fonksiyonu değeri bire eşit olan karar birimlerini "etkin", amaç fonksiyonu değeri birden küçük olan karar birimlerini "etkin olmayan" olarak nitelendiren, doğrusal programlama temeline dayalı bir analiz tekniğidir (Akar, 2011: 123-124; Özcan, 2014: 13). Parametrik olmayan bir analiz tekniği olan VZA'da, benzer girdileri ve çıktıları kullanan karar verme birimlerinin etkinliği ölçülmektedir. $\mathrm{Bu}$ yöntemden çoğunlukla, karmaşık girdi ve çıktıya sahip olan örgütlerin (örneğin, hastaneler, sağlık sistemleri, bankalar, vs.) etkinlikleri karşılaştırılırken faydalanılmaktadır (Bal ve Bilge, 2013: 2). 
VZA yönteminin, Charnes vd. 'nin (1978) Farrel (1957) tarafindan kaleme alınan "The Measurement of Productive Efficiency" isimli makaleyi temel alarak yazdıkları "Measuring the Efficiency of Decision Making Units" isimli makale ile ortaya atıldığı söylenebilir. Gündeme geldiği ilk şeklinde VZA, ölçeğe göre sabit getiri (CRS veya CCR) varsayımı altında tasarlanmışken Banker vd. (1984) tarafindan ölçeğe göre değişken getiri (VRS veya BCC) formuna dönüştürülerek etkinlik ölçümüne yeni bir boyut kazandırılmıştır (Gülsevin ve Türkan, 2012: 1; Demir vd., 2012: 171; Bal ve Bilge, 2013: 2). CRS ve VRS modelleri arasındaki fark ile ilgili şunlar söylenebilir; CRS modelinde girdilerdeki artış oranı ile çıktılardaki artış oranının aynı olması beklenirken VRS modelinde, girdilerdeki artış oranından farklı bir oranda çıktılarda değişim beklenir (Narc1, 2012: 122). Bununla birlikte, CRS modeli hem tamamen yönetsel performanstan kaynaklanan saf teknik etkinliği hem de karar verme biriminin büyüklüğünden kaynaklanan ölçek etkinliğini içererek toplam etkinliği ortaya koymaktadır. VRS modeli ise, büyüklük unsurunu göz ardı ederek, yani ölçek etkinliğini içermeyerek sadece saf teknik etkinliği ortaya koymaktadır. Bunun bir sonucu olarak, VRS modelinin kullanıldığı bir çalışmada etkin çıkan karar değişkeni sayısı, CRS modeline göre daha fazladır (Narc1, 2012: 122-123).

VZA'da karar verme birimlerinin etkin sayılmasını belirleyen diğer kriterler şunlardır (Charnes vd., 1981: 669):

(i) Bir karar verme birimi için, herhangi bir girdiyi artırmadan ve diğer herhangi bir çıtıyı azaltmadan bir çıktıyı artırmak mümkünse, o karar birimi etkin değildir (Çıktı odaklılık).

(ii) Bir karar verme birimi için, diğer herhangi bir girdiyi artırmadan ve hiçbir çıktıyı azaltmadan bir girdiyi azaltmak mümkünse, o karar birimi etkin değildir (Girdi odaklılık).

Görüldüğü üzere VZA'da ilgili karar biriminin etkin olmasını belirleyen faktörler, analizde CRS veya VRS modellerinden hangisinin kullanıldığına ve analizin girdi veya çıktı odaklı yapılmasına bağlı olarak değişebilmektedir. Bu çalışmada yöntem olarak, girdi odaklı VZA'nın hem CRS hem de VRS modelleri benimsenmiştir. Çalışmanın girdi odaklı olmasının nedeni, sağlık hizmetlerinde yönetimsel kontrolün çıktılardan ziyade girdiler üzerinde olmasıdır (Ayanoğlu vd., 2010: 51; Kocaman vd.,2012: 15). Analizler DEA-SOLVER 13 programı kullanılarak gerçekleştirilmiştir.

\section{Kisıtlılıklar ve Varsayımlar}

OECD üyesi 35 ülke bulunmaktadır. Fakat çalışma kapsamında yapılan araştırmalar sonucunda OECD üyesi 20 ülkeye ait veriler bulunduğundan çalışma bu 20 ülke ile sınırlıdır. Bu ülkeler, çalışmanın karar verme birimlerini oluşturmaktadır. OECD üyesi tüm ülkeleri kapsamına alamadığından ruh sağlığı hizmetleri performansının bütüncül bir şekilde değerlendirilememesi, çalışmanın önemli bir kısıtını oluşturmaktadır. $\mathrm{Bu}$ durum araştırmacılardan bağımsız olarak ülkelerin verilerini sistematik bir şekilde OECD, Dünya Bankası ve DSÖ gibi uluslararası örgütlere sağlıklı bir şekilde aktaramaması veya eksik veri vermesinden kaynaklanmaktadır.
Ruh sağlığı indikatörleri arasında; psikiyatr hekim sayısı, ruh sağlığı hizmetlerinde çalışan hemşire, sosyal çalışmacı, psikolog sayıları, psikiyatri hasta yatağı sayısı, ayakta veya yatarak sunulan psikiyatri hizmetleri, intihar hızı, psikoterapötik ilaç kullanma oranı ve genel bütçeden ruh sağlığı hizmetlerine ayrılan pay sayılmaktadır (WHO, 2014). $\mathrm{Bu}$ çalışmanın sağlıklı sonuçlar verebilmesi için sayılan indikatörlerin tümü değerlendirilmiş fakat eksik veriler sebebiyle çalışma kapsamına; 100.000 kişiye düşen psikiyatri hasta yatağı sayısı, 100.000 kişiye düşen psikiyatr sayısı, 100.000 kişiye düşen psikiyatri hemşiresi sayısı, 100.000 kişiye düşen psikolog sayısı ve her iki cinsiyet için 100.000 kişiye düşen toplam kaba intihar hızı alınmıştır. Literatür kısmında da belirtildiği gibi ruh sağlığı hizmetleri ülkeler tarafından politika önceliği düşük olan hizmetler arasında görülmektedir. Bu nedenden ülkeler, ruh sağlı̆̆ hizmetleri performansını değerlendirecek verileri önemsememekte, toplamamakta veya sistematik bir şekilde uluslararası veri tabanlarına aktarmamaktadır. $\mathrm{Bu}$ durum araştırmacılar için önemli bir dezavantajdır. Sağlık sektörü gibi teknoloji ve emek yoğun örgütlenmelerde güncel veriler hayati önem arz etmektedir. Dolayısıyla çalışma kapsamına alınan indikatörlerin güncel olması arzu edilmiş olmakla birlikte, sayılan sebeplerden ötürü güncel verilere ulaşılamamıştır. Ayrıca, VZA yöntemine göre karar verme birimlerinin (ülkelerin) sayısının minimum, girdi değişkeni sayısı ile çıktı değişkeni sayının çarpımı ya da toplamının 23 katı kadar olması doğru sonuçlar elde edilebilmesi için önemlidir (Yıldırım, 2010: 144; Aladağ vd., 2018:1). Güncel verilerin kullanılması durumunda karar verme birimi sayıs1 oldukça düştüğü için analiz varsayımları sağlanamamaktadır. Sayılan sebeplerden en sağlıklı verilerin 2011 yılına ait veriler olduğu görülmüş ve dolayısıyla analiz, bu yılın verileri kullanılarak gerçekleştirilmiştir.

$\mathrm{Bu}$ kısıtlılıkların yanı sıra, çalışmanın yöntemi olan VZA'dan kaynaklanan bazı kısıtlılıklar ve varsayımlar da söz konusudur. Bu kısıtlılıklar ve varsayımlar şu şekilde belirtilebilir:

(i) Analizler, diğer faktörler sabit olmak koşulu ile seçilen temsili girdi ve çıktı değişkenleri ile gerçekleştirilmiştir ve çıkan sonuçların bu kısıtın dikkate alınmak suretiyle değerlendirilmesinde yarar görülmektedir.

(ii) VZA'nın; kullanılan değişkenlerden, analizin girdi odaklı veya çıktı odaklı olmasından ya da ölçeğe göre sabit getirili veya değişken getirili olmasından etkilendiği göz önünde bulundurulmalıdır. Bu açıdan bakıldığında, analizde kullanılan girdi ve çıktı değişkenlerinin veya modellerin değiştirilmesi halinde etkinlik skorlarının değişebileceği unutulmamalıdır.

(iii) VZA'da karar verme birimlerinin etkinliği, etkinliği en iyi olan birimlerin göstermiş olduğu performansa göre şekillenen bir etkinlik sınırına olan uzaklıklarına göre değerlendirilmektedir. Bu sınırın genel kabul 
görmüş standart bir sınır olamayabileceği gerçeği söz konusudur.

\section{Bulgular ve Yorumlar}

Çalışmanın verileri, OECD ve DSÖ veri tabanlarından alınmış olup 2011 yılı verilerini kapsamaktadır. Çalışmada çıktı olarak kullanılan kaba intihar hızına ait veriler OECD veri tabanından elde edilirken çalışmada girdi olarak kullanılan değişkenler (100.000 kişiye düşen psikiyatri hasta yatağ1 sayısı, 100.000 kişiye düşen psikiyatr sayısı, 100.000 kişiye düşen psikiyatri hemşiresi sayısı ve 100.000 kişiye düşen psikolog sayısı) DSÖ veri tabanından elde edilmiştir. Tablo 1'de, çalışmada kullanılan girdi ve çıktı değişkenleri sunulmaktadir.

Tablo 1. Çalışmada Kullanılan Girdi ve Çıktı Değişkenleri

\begin{tabular}{|c|c|}
\hline \multirow{4}{*}{ :ं̈ } & Psikiyatri hasta yatağı sayısı (100.000 kişiye \\
\hline & Psikiyatr sayısı (100.000 kişiye düşen) (PS) \\
\hline & Psikiyatri hemşiresi sayısı (100.000 kişiye düşen) (PHS) \\
\hline & Psikolog sayısı (100.000 kişiye düşen) (PSI) \\
\hline$\frac{\underline{E}}{U}$ & $\begin{array}{l}\text { Her iki cinsiyet için toplam kaba intihar hızı (100.000 } \\
\text { kişiye düşen), } 1 \text { /Kaba İntihar Hızı (INT) }\end{array}$ \\
\hline
\end{tabular}

Çalışma kapsamında verilerine ulaşılabilen 20 OECD ülkesine ait veriler Tablo 2'de sunulmaktadır.

Tablo 2. Seçilmiş OECD Ülkelerine Ait Veriler

\begin{tabular}{|c|c|c|c|c|c|}
\hline Ülkeler & & (PS) & & (PSI) & $1 /(\mathrm{I}$ \\
\hline Avustralya & 28,91 & 12,76 & 69,54 & 62,48 & 0,09 \\
\hline Belçika & 25,59 & 17 & 0,04 & 1,34 & 0,06 \\
\hline Kanada & 36 & 12,61 & 65 & 46,56 & 0,10 \\
\hline Çekya & 13,41 & 11,85 & 28,24 & 2,03 & 0,07 \\
\hline Fransa & 22,72 & 22,35 & 86,21 & 47,9 & 0,06 \\
\hline Macaristan & 72,21 & 6,52 & 21,93 & 2,47 & 0,04 \\
\hline İzlanda & 42,82 & 19,74 & 37,96 & 31,89 & 0,11 \\
\hline İrlanda & 19,61 & 6,06 & 112,8 & 3,53 & 0,08 \\
\hline İtalya & 10,95 & 7,81 & 19,28 & 2,58 & 0,16 \\
\hline Japonya & 73,12 & 10,1 & 102,5 & 3,99 & 0,05 \\
\hline Güney Kore & 41,24 & 5,12 & 21,61 & 1,12 & 0,03 \\
\hline Meksika & 0,08 & 1,57 & 2,62 & 0,55 & 0,19 \\
\hline Yeni Zelanda & 21,35 & 9,76 & 89,32 & 13,78 & 0,09 \\
\hline Norveç & 130 & 30,77 & 120,8 & 0,45 & 0,08 \\
\hline Polonya & 14,3 & 5,13 & 17,64 & 3,6 & 0,07 \\
\hline Portekiz & 9,41 & 6,14 & 12,13 & 2,11 & 0,12 \\
\hline Slovenya & 8,89 & 7,06 & 69,68 & 4,54 & 0,05 \\
\hline İsveç & 34,91 & 3,55 & 28,9 & 0,93 & 0,09 \\
\hline Türkiye & 5,56 & 2,13 & 2,22 & 1,62 & 0,59 \\
\hline A.B.D & 14,36 & 7,79 & 3,07 & 29,03 & 0,08 \\
\hline Ortalama & 31,27 & 10,29 & 45,58 & 13,13 & 0,11 \\
\hline
\end{tabular}

Çalışma kapsamında, değişkenler arasında yüksek ilişki düzeyi olup olmadiğı kontrol edilmek istenmiştir. $\mathrm{Bu}$ kapsamda yapılan korelasyon analizi sonucunda, çalışmanın değişkenleri arasında yüksek düzeyde bir korelasyon olmadığı görülmüştür (Tablo 3).
Tablo 3. Değişkenler Arası Korelasyon Tablosu

\begin{tabular}{ccccccc}
\hline \multicolumn{1}{c}{} & \multicolumn{1}{c}{ PYHS } & PS & PHS & PSI & INT \\
\hline \multirow{2}{*}{ PYHS } & $\mathrm{r}$ & 1 & & & & \\
\cline { 2 - 7 } & $\mathrm{p}$ & & & & & \\
\hline \multirow{2}{*}{ PS } & $\mathrm{r}$ &, $612^{* *}$ & 1 & & & \\
\cline { 2 - 7 } & $\mathrm{p}$ &, 004 & & & & \\
\hline \multirow{2}{*}{ PHS } & $\mathrm{r}$ &, $511^{*}$ &, $508^{*}$ & 1 & & \\
\cline { 2 - 7 } & $\mathrm{p}$ &, 021 &, 022 & & & \\
\hline \multirow{2}{*}{ PSI } & $\mathrm{r}$ &,- 060 &, 364 &, 242 & 1 & \\
\cline { 2 - 7 } & $\mathrm{p}$ &, 801 &, 115 &, 304 & & \\
\hline \multirow{2}{*}{ INT } & $\mathrm{r}$ &,- 295 &,- 295 &,- 316 &,- 123 & 1 \\
\cline { 2 - 7 } & $\mathrm{p}$ &, 207 &, 207 &, 174 &, 604 & \\
\hline
\end{tabular}

** $\mathrm{p}<0,01, * \mathrm{p}<0,05$

Seçilmiş OECD ülkelerinin VRS modeline göre ruh sağlı̆̆ hizmetlerindeki etkinlik skorları Grafik 1'de sunulmaktadır. Buna göre, bu çalışma kapsamında analize dâhil edilen 20 ülkenin 4(\%20)'ünün (Belçika, Norveç, Türkiye, Meksika) sunduğu ruh sağlığı hizmetlerinde etkinliği yakaladığı görülmektedir. Bu 20 ülkenin, VRS modeline göre ruh sağlığı hizmetlerindeki etkinlik skorları ortalaması $0,41 \pm 0,33$ 'dır. Bulunan ortalama, analiz kapsamındaki ülkelerin VRS Modeline göre düşük etkinlik skorlarına sahip olduğunu göstermektedir.

Grafik 1. VRS Modeline göre VZA sonuçları

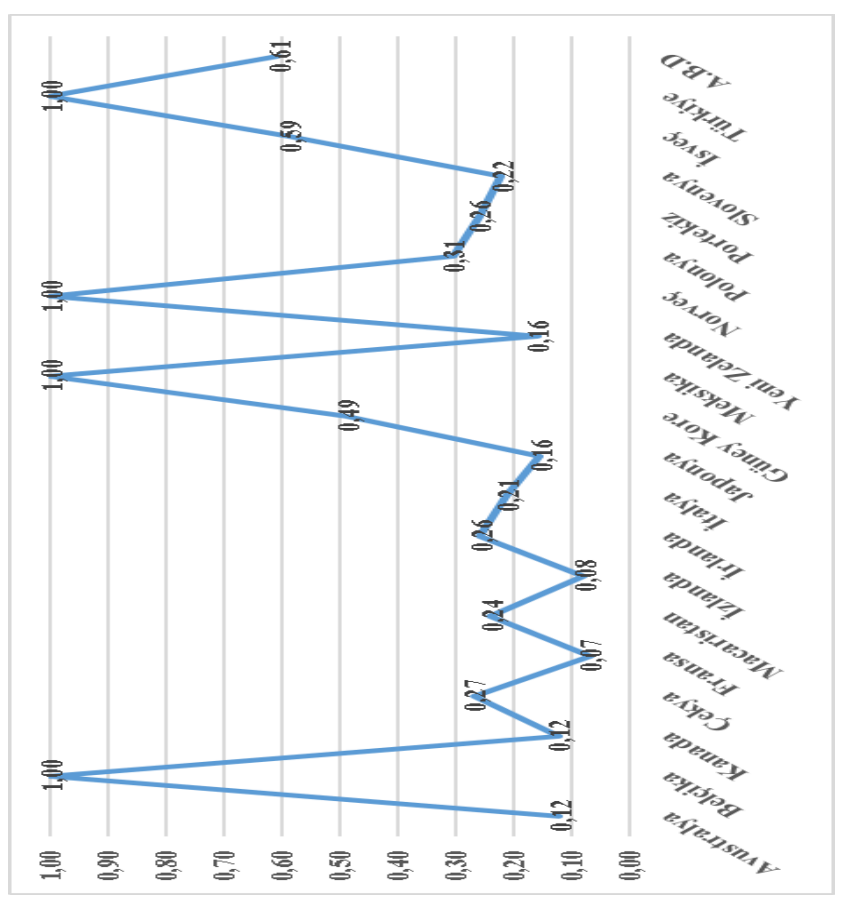

Seçilmiş OECD ülkelerinin CRS modeline göre ruh sağlığ hizmetlerindeki etkinlik skorları Grafik 2'de sunulmaktadır. Buna göre, bu çalışma kapsamında analize dâhil edilen 20 ülkenin 3(\% 15)'ünün (Belçika, Meksika, Türkiye) sunduğu ruh sağlığı hizmetlerinde etkinliği yakaladığı görülmektedir. $\mathrm{Bu} 20$ ülkenin, CRS modeline göre ruh sağlı̆̆ hizmetlerindeki etkinlik skorları ortalaması $0,24 \pm 0,35$ 'dır. Bulunan ortalama, analiz kapsamındaki ülkelerin CRS Modeline göre düşük etkinlik skorlarına sahip olduğunu göstermektedir. 
Grafik 2. CRS Modeline göre VZA sonuçları

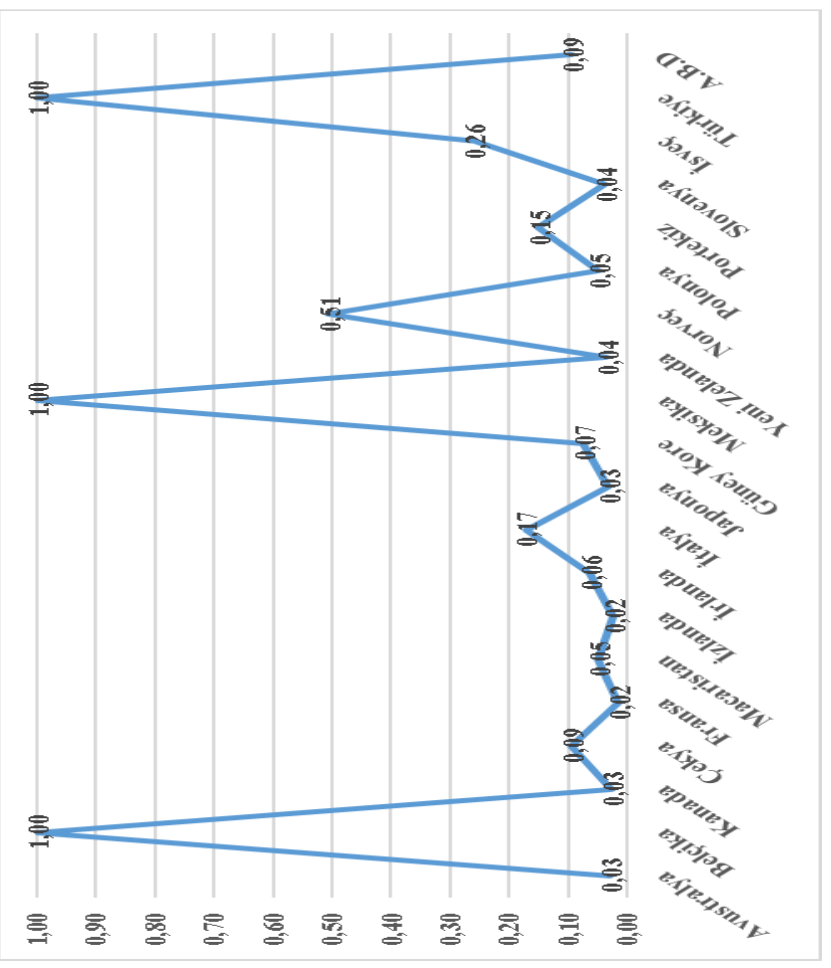

Tablo 4'te, seçilmiş OECD ülkelerinden VRS ve CRS modellerine göre etkin olanların etkin olmayanlara referans olma sayıları gösterilmektedir. Buna göre, VRS modelinde en fazla referans gösterilen ülke Meksika (16) iken CRS modelinde en fazla referans gösterilen ülke Türkiye (17)'dir. Buradan VRS ve CRS modellerine göre en çok referans gösterilen ülkelerin (Meksika ve Türkiye), bu çalışmada kullanılan girdiler ve çıktılar bakımından etkin olmayan ülkelerinkine benzer göstergelere sahip oldukları ve bu yüzden etkin çıkan diğer ülkelere nispeten daha çok referans gösterildikleri yorumu yapılabilir.

Tablo 4. VRS ve CRS Modellerine Göre Etkin Çıkan Ülkelerin Diğer Ülkelere Referans Olma Sayıları

\begin{tabular}{ccc}
\hline Ülkeler & $\begin{array}{c}\text { VRS Modeline Göre Referans } \\
\text { Olma }\end{array}$ & $\begin{array}{c}\text { CRS Modeline Göre } \\
\text { Referans Olma }\end{array}$ \\
\hline Belçika & 1 & 1 \\
Meksika & 16 & 5 \\
Norveç & 5 & Etkin Değil \\
Türkiye & 1 & 17 \\
\hline
\end{tabular}

\section{Sonuç ve Öneriler}

Bu çalışmada, OECD üyesi 20 ülkenin ruh sağlığı hizmetleri performansı karşılaştırılmıştır. Literatür incelendiğinde, ülkeler bazında ruh sağlığı hizmetleri performansının karşılaştırıldığı başka bir çalışmaya rastlanmamıştır ki bu durum, çalışmanın en güçlü yönünü oluşturmaktadır.

Çalışmada elde edilen sonuçlar incelendiğinde, gelişmiş bazı ülkelerin (Japonya, Fransa, A.B.D., Güney Kore, Kanada, Avustralya, İzlanda, Yeni Zelanda) düşük etkinlik skorlarına sahip oldukları görülmektedir. Bunun temel sebebinin bu ülkelerde, çalışmanın çıktısı olan kaba intihar hızının yüksek olması ile açıklanabileceği düşünülmektedir. Bunun yanı sıra bu ülkelerin, diğer ülkelere kıyasla girdilerde daha fazla kaynak kullanmaları da düşük etkinlik skorlarına zemin hazırlayan sebeplerden biri olarak görülebilir.
Yukarıda sayılan, iktisadi açıdan gelişmiş ülkelerde kaba intihar hızının yüksek olması, ekonomik faktörler dışındaki faktörlere atfedilebilir. Yaşanan kültürel çatışmalar, 1rkçılık, doğal afetler, savaşlar, vb. etmenler kişileri intihara sürükleyebilmektedir (Demir ve Çakmak, 2017: 99). Örneğin, Japonya ve Güney Kore gibi gelişmiş uzak doğu ülkelerinde intihar kültürünün olması, diğer ülkelerde ise; mental hastalıklar, alkol ve madde kullanımı, sosyal destekten yoksun olmak, sosyal izolasyon, aşırı bireyselleşme gibi faktörlerin intihar hızını artırdığı düşünülebilir. Gelişmekte olan ve çalışma kapsamında etkin bulunmayan bazı ülkelerde (Macaristan, Slovenya, Polonya, Çekya, vb.) de kaba intihar hızının yüksek olduğu görülmektedir. $\mathrm{Bu}$ ülkelerde kaba intihar hızının yüksek olması, gelişmiş ülkelerin tersine ekonomik sorunlarla açıklanabilir.

Çalışma kapsamındaki ülkeler arasında en düşük intihar hızına sahip olan ülke Türkiye'dir ki bu yüzden hem VRS hem de CRS modellerinde etkin çıkmış ve CRS modeline göre en fazla referans gösterilen ülke olmuştur. Türkiye'de intihar hızının düşük olmasının nedenleri arasında; dini inanç, kültür, toplumsal kontrol, bireyselleşmenin görece daha az olması, aile yapısının güçlü olması gibi etmenler sayılabilir. Türkiye'nin her iki modele göre de etkin çıkmasına sebep olan bir diğer faktör de, diğer ülkelere göre nispeten düşük girdi kullanımıdır. Bunun nedenleri arasında; ruh sağlığı hizmetleri için ayrılan özel bir bütçenin olmaması ve hâlihazırda ruh sağlığı hizmetlerinde kullanılan kaynakların yetersizliği, nitelikli personel sayısının yetersizliği, diğer ülkelere kıyasla düşük psikiyatri hasta yatağına sahip olması, toplum temelli ruh sağlı̆̆ hizmetlerinin yaygınlaştırılmamış olması gibi faktörler sayılabilir.

Çalışma sonucunda elde edilen bulgular doğrultusunda ülkelerin; kaba intihar hızını düşürecek önlemler almaları ve bu yönde stratejiler geliştirmeleri, toplum tabanlı ruh sağlı̆̆ hizmetlerinin desteklenmesi, ruh sağlığı hizmetlerine erişimde eşitlik ve hakkaniyetin gözetilmesi, ruh sağlı̆̆ hizmetlerine gerekli yatırımların yapılması, ruh sağlığı hizmetleri için ayrılan kaynakların etkin ve rasyonel şekilde kullanılması önerilmektedir.

\section{Kaynakça}

Akar, Ç. (2011). 2. ve 3. Basamak Sağlık Kurumlarl Finansal Tablo Konsolidasyonu. Ankara: Sağlık Bakanlığı Yayınları.

Akarçay, D. (2013). Türkiye'de Yürütülen Ruh Să̆lı̆̆ Hizmetleri Politikalarının Değerlendirilmesi. Yüksek Lisans Tezi. Ankara: Hacettepe Üniversitesi Sosyal Bilimler Enstitüsü.

Aladağ Z., Alkan A., Güler, E., \& Özdin, Y. (2018). Akademik Birimlerin Veri Zarflama Analizi ve Promethee Yöntemleri ile Performans Değerlendirmesi: Kocaeli Üniversitesi Örneği. Journal of Institue of Science and Technology 34(1), 1-13.

Ayanoğlu, Y., Atan, M., \& Beylik, U. (2010). Hastanelerde Veri Zarflama Analizi (VZA) Yöntemiyle Finansal Performans Ölçümü ve Değerlendirilmesi. Sağlıkta Performans ve Kalite Dergisi,2(2), 40-62. 
Bal, V., \& Bilge, H. (2013). Eğitim ve Araştırma Hastanelerinde Veri Zarflama Analizi İle Etkinlik Ölçümü. Manas Sosyal Araştırmalar Dergisi, 2(2), 1-14.

Banker, D. R., Charnes, A., \& Cooper, W. W. (1984). Some Models for Estimating Technical and Scale Inefficiencies in Data Envelopment Analysis. Management Science, 30(9), 1078-1092.

Birleşmiş Milletler (2014). Mental Health Matters Social Inclusion of Youth With Mental Health Conditions. (Erişim Tarihi: 18.04.2018), http://www.un.org/esa/socdev/documents/youth/youthmental-health.pdf

Bloom, D. E., Cafiero, E., Jané-Llopis, E., AbrahamsGessel, S., Bloom, L. R., Fathima, S., ... \& O'Farrell, D. (2012). The global economic burden of noncommunicable diseases (No. 8712). Program on the Global Demography of Aging. (Erişim Tarihi: 1.04.2018),

http://apps.who.int/medicinedocs/documents/s18806en/s 18806en.pdf

Charnes A., Cooper, W., \& Rhodes, E. (1978). Measuring the Efficiency of Decision Making Units. European Journal of Operational Research, 2(6), 429-444.

Charnes A., Cooper, W., \& Rhodes, E. (1981). Evaluating Program and Managerial Efficiency: An Application of Data Envelopment Analysis to Program Follow Through. Management Science 27(6), 668-697.

Demir, H., \& Çakmak, C. (2017). Halk Sağlığı Problemi Olarak İntiharlar: Türkiye Örneği. Să̆llk ve Sosyal Politikalara Bakış Dergisi, 1(2), 94-117.

Demir, P., Derbentli, Ö., \& Sakarya, E. (2012). Kars İlinde Bulunan Mandıraların Etkinliğinin Veri Zarflama Analizi İle Ölçülmesi. Kafkas Üniversitesi Veteriner Fakültesi Dergisi, 18 (2), 69-176.

Farrell, M. J. (1957). The Measurement of Productive Efficiency. Journal of the Royal Statistical Society Series, 120(3), 253-290.

Gülsevin, G., \& Türkan, A. H. (2012). Afyonkarahisar Hastanelerinin Etkinliklerinin VZA ile Değerlendirilmesi. Afyon Kocatepe Üniversitesi Fen Bilimleri Dergisi, 12(2), 1-8.

Horton, R. (2007). Launching a New Movement for Mental Health. The Lancet, 370(9590), 806. https://doi.org/10.1016/S0140-6736(07)61243-4

Jacobs, R., \& Mcdaid, D. (2009). Performance Measurement in Mental Health Services. In: Performance Measurement for Health System Improvement: Experiences, Challenges and Prospects,(s.426-471), Smith, Peter C. vd. (Ed.), United Kingdom: Cambridge University Press.

Knapp, M., McDaid, D., Amaddeo, F., Constantopoulos, A., Oliveira, M. D., Salvador-Carulla, L., ... \& Mheen Group. (2007). Financing mental health care in Europe. Journal of mental health, 16(2), 167-180.

Kocaman, A. M., Mutlu, M. E., Bayraktar, D., \& Araz, Ö. (2012). OECD Ülkelerinin Sağlık Sistemlerinin Etkinlik Analizi. Endüstri Mühendisliği Dergisi 23(4), 14-31.
Narcı, H. Ö. (2012). Sağlık Kurumlarında Verimlilik Ölçümü ve Yöntemleri. İçinde: Sağlık Kurumlarında Operasyon Yönetimi, (s.112-139), İsmet Şahin \& Narc1 H.Özgen (Ed.). Eskişehir: T.C. Anadolu Üniversitesi Yayını.

OECD (2018a). Mental Health Systems in OECD Countries. (Erişim Tarihi: 29.08.2018), http://www.oecd.org/els/health-systems/mental-healthsystems.htm

OECD (2018b). OECD Health Data. (Erişim Tarihi: 29.08.2018), https://data.oecd.org/health.htm

Özcan, Y. (2014). Health Care Benchmarking and Performance Evaluation. New York: Springer Science+ Business Media, Second Edition.

Songur, C., Saylavcı, E., \& Kıran, Ş. (2017). Avrupa'da ve Türkiye'de Ruh Sağlığı Hizmetlerinin Karşılaştırmalı Olarak İncelenmesi. Social Sciences Studies Journal, 3(4), 276-289.

Taipale, V. (2001). Mental Health and Quality of Mental Health Care. Medicine \& Law, 20(4), 531-542.

Vigo, D., Thornicroft, G., \& Atun, R. (2016). Estimating the True Global Burden of Mental İllness. The Lancet Psychiatry, 3(2), 171-178.

WHO (2003). Mental Health in the WHO European Region. (Erişim Tarihi: 8.04.2018), http://www.euro.who.int/_data/assets/pdf_file/0004/21 5275/RC63-Fact-sheet-MNH-Eng.pdf

WHO (2013). Investing in Mental Health: Evidence For Action. (Erişim Tarihi: 18.04.2018), http://apps.who.int/iris/bitstream/handle/10665/87232/9 789241564618_eng.pdf;jsessionid=575422BB0926B4B A477A8320CBC2EDB7? sequence $=1$

WHO (2014). Indicator Code Book, Mental Health Resources. (Erişim Tarihi: 29.08.2018), http://www.who.int/gho/mental_health/mental_health_i ndicatorbook.pdf

WHO (2018a). Mental Health: a State of Well-Being. (Erişim Tarihi: 28.08.2018), http://www.who.int/features/factfiles/mental_health/en/

WHO (2018b). WHO Database. (Erişim Tarihi: 28.08.2018), https://www.who.int/healthinfo/statistics/en/

Yıldırım, E. (2010). Veri Zarflama Analizinde Girdi Ve Çıktıların Belirlenmesindeki Kararsızlık Problemi İçin Temel Bileşenler Analizine Dayalı Bir Çözüm Önerisi. Ístanbul Üniversitesi Işsletme Fakültesi Dergisi, 39(1), 141-153. 